\title{
O AMBIENTE INFORMAL COMO FACILITADOR NO PROCESSO DE ASSIMILAÇÃO DOS CONTEÚDOS DE BIOLOGIA
}

\author{
Sabrina Buqueroni Alves ${ }^{1}$ \\ Osvaldo de Oliveira Ponte Junior ${ }^{2}$ \\ Elaine Gimenez Guimarães ${ }^{3}$ \\ Gustavo Lemos Rocha ${ }^{4}$
}

Resumo: O conteúdo de Ciências biológicas é visto por muitos alunos como algo complexo, que necessita apenas ser decorado para garantir o avanço nas séries do ensino básico. No entanto, nos últimos anos diversas metodologias vem sendo utilizadas, visando tornar o conteúdo teórico palpável. Seguindo esta proposta o presente trabalho realizado com alunos da $3^{a}$ série do ensino médio da escola Aristeu Aguiar, teve como objetivo apresentar, revisar conceitos ecológicos e sensibilizar a comunidade escolar, quanto a percepção ambiental, utilizando aulas de campo após aulas expositivas sobre ecologia. Após a aplicação de um questionário, observamos resultados positivos, destacando que o uso de aulas de campo conduzida por pessoas capacitadas e a aplicação de teoria durante a atividade, é uma ferramenta eficaz no ensino de biologia.

Palavras-chave: Aulas de campo; Ecologia; Assimilação dos conteúdos.

\footnotetext{
1 Ciências Biológicas Licenciatura, Universidade Federal do Espírito Santo, Brasil. E-mail: sabrinabuqueroni21@gmail.com.

2 Ciências Biológicas Licenciatura, Universidade Federal do Espírito Santo, Brasil. E-mail: osvaldojrxvi@hotmail.com.

3 Ciências Biológicas Licenciatura, Universidade Federal do Espírito Santo, Brasil. E-mail: elainegimenez@gmail.com.

${ }^{4}$ Centro de Biociências e Biotecnologia/Universidade Estadual do Norte Fluminense Darcy Ribeiro, Brasil. Email: gustavolrocha@yahoo.com.br.
} 